\title{
Calculating ISQ Primary Stability of a Dental Implant through Micromotion
}

\author{
David Pammer ${ }^{*}$ \\ ${ }^{1}$ Department of Materials Science and Engineering, Faculty of Mechanical Engineering, Budapest University of Technology and \\ Economics, H-1111 Budapest, Műegyetem rkp. 3., Hungary \\ * Corresponding author, e-mail: pammer@eik.bme.hu
}

Received: 10 April 2019, Accepted: 03 June 2019, Published online: 17 December 2019

\begin{abstract}
There are several types of primary and secondary stability measuring methods, but there are no calculating methods to determine direct primary stability. The aim of this work is to make a calculation method for primary stability. The out coming result of the calculation should be the same form and unit as available in the clinical and used RFA (Resonance Frequency Analysis) method, especially the ISQ (Implant Stability Quotient). Dental implant analog screws were inserted in bone modelling standard PUR (Polyurethane) solid foam blocks, and the insertion torque and the micromotion was monitored. The ISQ values of the inserted screws were measured also. On the basis of results, the characteristic equation was determined, which showed an excellent correlation ( $r=0.96)$ between the micro mobility and ISQ. To simulate the micro mobility of an inserted screw with FEA (Finite Element Analysis) in any case of the change the bone material properties is not difficult instead of in vitro and in vivo examinations. Using the simulation results and the characteristic equation the clinically used ISQ value could be determinable. Thanks to this simple method, it is easy to monitor virtually the stability change in any lesion of bone structure. As a result of the conducted measurements and simulations, it can be concluded that the ISQ value, which represent the implant primary stability, can be calculated via FEA. With this simulation method, it is possible to predict and monitor pre-clinically the primary stability of dental implants with new geometries.
\end{abstract}

\section{Keywords}

primary stability, micro mobility, Implant Stability Quotient (ISQ), Finite Element Analysis (FEA), dental implant

\section{Introduction}

There are different methods to measure an implant primary and secondary stability. These methods can be grouped according their measuring methods type (Fig. 1) [1-7]. There are some type of measuring methods (marked on Fig. 1 with *) which can perform according standards, but these standards are not direct for dental implants, but for metal medical bone screws (e.g. ASTM F543-17, ISO/TS 22911:2016 [8, 9]). Some types of these methods do not allow to measure primary and secondary stability as well, or to monitor the stability change during the healing period. There are also methods, which are not allowed to use in vivo.

There are scientific publications which discuss how can be simulated some of these measuring methods and how influence the implant type (shape, threads, surface) the stress distribution around the implant depending of the bone material properties and structures [10-14]. The direct simulation of a screw implant stability is not a clear process. The direct

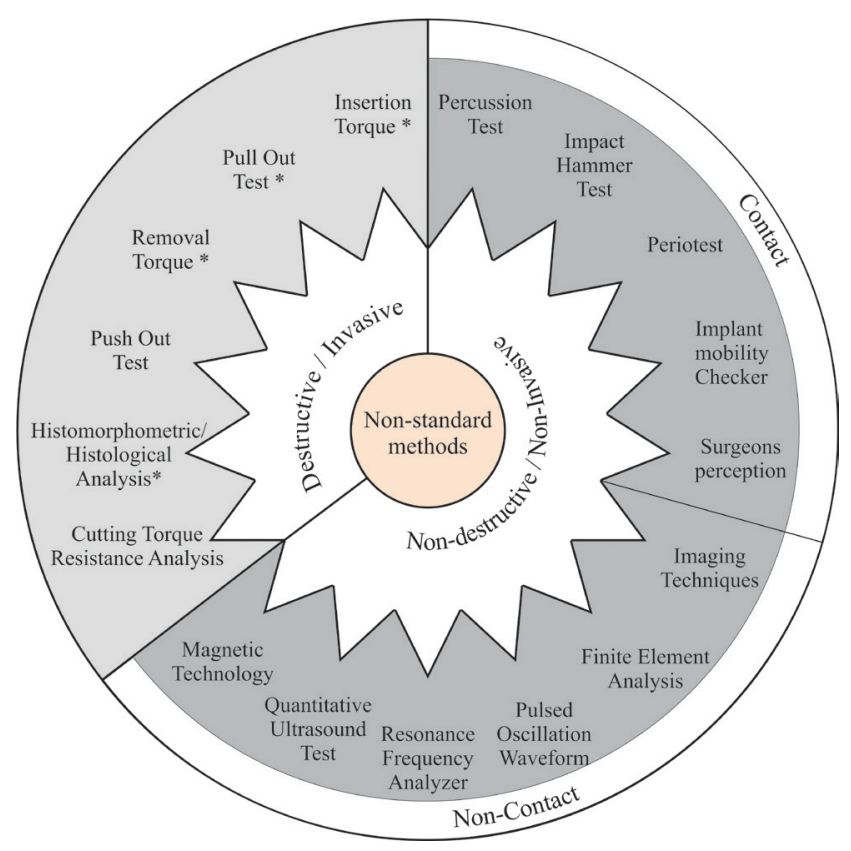

Fig. 1 Implant stability measuring methods 
simulation of the ISQ (Implant Stability Quotient) stability with an easy implementable normal static load case is not possible because the ISQ value based on RFA (resonance frequency analysis) measurement and it is a dynamic load. Due to this, the ISQ is determinable just indirect way or direct with a modal analysis [15-17]. The ISQ value is an integer between 0 and 100, where four main range was determined to show the osseointegration stages. The lowest range, where the implant has weak stability and difficult the outcome is under 60 . The next range is between 60 and 65 , which is called traditional range. Traditional range mean the implant need healing time without loading. The range between 66 and 70 is called early loading range, where the implantologist can decide what is the earliest time as possible to load the implant. Over 70 the implant has a perfect stability, which let the patient to load immediately the implant $[18,19]$. The ISQ value can give result for primary and secondary stability as well, but there are publications which analyses the big standard deviation of this method [20-22]. After the literature overview, there are results for the correlation between ISQ and mechanical stability measuring methods like insertion torque, pull-out test and micromotion. The measuring of the insertion torque or the pull out test are not allow the monitoring the stability by time, because they let it do with one implant just one time. The definition of micromotion is the following: a displacement between bone and implant, which displacement above $150 \mu \mathrm{m}$ can cause the failure of the osseointegration and can induce fibrous tissue connection instead of bony hard tissue connection. Micromotion is measured under lateral static load above the bone level [23-26]. According to the definition of the micromotion, it is possible to monitor the osseointegration stage with the use of low forces during the healing time. Micromotion correlates to the stability, which means the micromotion of a screw implant decreases, when the osseointegration growths according to the bone regeneration. The implant micro mobility gives more information about the osseointegration than micromotion. Micro mobility shows the strength of the bone-implant connection. The unit is $\mu \mathrm{m} / \mathrm{N}$, and shows the effect of $100 \mathrm{~N}$ lateral force above $10 \mathrm{~mm}$ of bone level. This value depends on the implant size, geometry and the surrounding bone mechanical properties [27-30]. Thanks to the correlation between micromotion and ISQ, micro mobility is also correlated to ISQ. This is the reason why micro mobility was chosen to simulate numerically and calculated from the result the clinically often-used ISQ value. This method will give a possibility to check easily and virtually novel implant's ISQ value or the change of the ISQ value of an inserted implant due to the dramatic change of the bone's physical properties. The aim of the research was to prove the fact, that finite element analysis (FEA) can be used easily to determine ISQ stability of the bone screw implant, and the calculated values correlated to the real stability values, which was measured by clinically used machines. The hypothesis of the research: the clinically used stability measured values (ISQ) correlated to the numerical simulated micromotion values and it is possible to calculate ISQ from the micro mobility result.

\section{Materials and Methods}

\subsection{Materials}

During the laboratory in vitro examinations standard polyurethane (PUR) solid foam blocks were used to model the healthy bone material, which blocks meet the standard ASTM F-1839 [31]. Eight different densities of solid foam blocks were used (Table 1) [32].

For the modelling of a dental implant, simple tapping screw with hexagonal head was used. In the middle (center) of the screw, a tapped hole was made to adopt the magnetic beam, which was needed to the RFA stability test.

Table 1 Material properties of the standard PUR solid foam blocks

\begin{tabular}{|c|c|c|c|c|c|c|c|c|}
\hline \multirow{2}{*}{$\begin{array}{l}\mathrm{Nr} . \\
-\end{array}$} & \multirow{2}{*}{$\begin{array}{c}\text { Density } \\
\text { PCF }\end{array}$} & \multirow{2}{*}{$\begin{array}{c}\text { Porosity } \\
-\end{array}$} & \multicolumn{2}{|c|}{ Compressive } & \multicolumn{2}{|c|}{ Tensile } & \multicolumn{2}{|c|}{ Shear } \\
\hline & & & $\begin{array}{c}\text { Strength } \\
(\mathrm{MPa})\end{array}$ & $\begin{array}{c}\text { Modulus } \\
(\mathrm{MPa})\end{array}$ & $\begin{array}{c}\text { Strength } \\
(\mathrm{MPa})\end{array}$ & $\begin{array}{l}\text { Modulus } \\
(\mathrm{MPa})\end{array}$ & $\begin{array}{c}\text { Strength } \\
(\mathrm{MPa})\end{array}$ & $\begin{array}{c}\text { Modulus } \\
(\mathrm{MPa})\end{array}$ \\
\hline 01 & 5 & 0.07 & 0.6 & 16 & 1 & 32 & 0.59 & 7.1 \\
\hline 02 & 10 & 0.14 & 2.2 & 58 & 2.1 & 86 & 1.6 & 19 \\
\hline 03 & 12 & 0.16 & 3.2 & 81 & 2.5 & 112 & 2.1 & 24 \\
\hline 04 & 15 & 0.20 & 4.9 & 123 & 3.7 & 173 & 2.8 & 33 \\
\hline 05 & 20 & 0.27 & 8.4 & 210 & 5.6 & 284 & 4.3 & 49 \\
\hline 06 & 25 & 0.34 & 12.9 & 317 & 8.8 & 399 & 5.9 & 68 \\
\hline 07 & 30 & 0.41 & 18 & 445 & 12 & 592 & 7.6 & 87 \\
\hline 08 & 35 & 0.47 & 0.47 & 24.4 & 15.6 & 713 & 9.4 & 108 \\
\hline
\end{tabular}


The magnetic beam was produced by the manufacturer of the RFA machine. The magnetic beam is for a commercial used dental implant. The tapping screw geometry was similar to a commercial available dental implant (Fig. 2). The Table 2 shows the screw's geometrical parameters.

\subsection{Methods}

In the clinical life, implants must be inserted according to the surgical/insertion protocol. This protocol contains the drilling protocol as well. The protocol determines which drill must be used depending on the implant geometry (diameter, length, pitch, profile, tapping, etc.) and the bone physical properties. In the present study, thanks to the simple geometry of the screw, the drilling protocol was used a screw's core diameter drill. With this drill, five holes perpendicular to the surface were drilled into the eight PUR solid foams. The drilled holes depth was approximately three mm bigger then the screw's length.

(a)

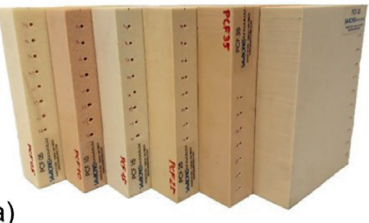

(b)
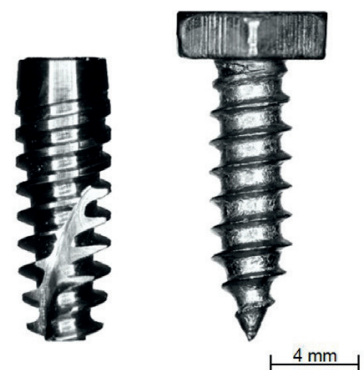

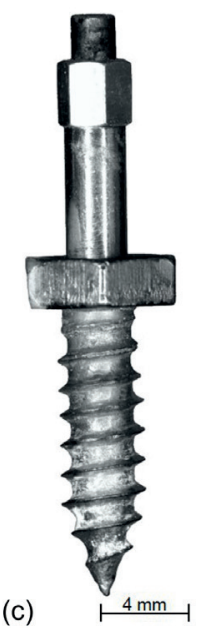

(c)
The biomechanical examination of the implant modeling screw was made with a tensile test machine (Instron 5965 - Instron Norwood, MA, USA) with a special head (for rotation) and pins (for micromotion). The measurements were done according to the following steps:

1. Insertion of the screws into the drilled holes of the PUR solid foams with the tensile test machine and registered the torque-rotation functions. The screws were inserted $0.5 \mathrm{~mm}$ above the "bone level".

2. After the insertion of the screws, one of them from each type of PUR solid foams was cut out, and cross section analysis was made (Stereo microscope Olympus SZX16), to see the compressed material structure around the screw direct after the insertion.

3. Following the inserting process, the magnetic beam was mounting with "finger-tight" (approximately 5-8 Ncm tightening torque) into the screw and with the RFA machine (Osstell ISQ - Osstell AB, Gothenburg, Sweden) the primary ISQ stability of the screw was measured [33] (Fig. 3).

4. Micromotion measurement were done with tensile test machine (Instron 5965 - Instron Norwood, MA, USA) according to the definition of micro mobility. A special beam was inserted into the screws to give the $10 \mathrm{~mm}$ distance from the bone level.

\subsection{Simulation}

The simulation was made with Autodesk Simulation Mechanical 2017 software. The material parameters for PUR solid foam blocks were used from Table 1. The screw material parameter was defined from the software's material library as titanium (Ti6Al4V) as the most used material for commercial dental implants.

Fig. 2 (a) The standard PUR bone modelling solid foam blocks. (b) The geometrical analogy between the real dental implant and the chosen tapping screw. (c) The inserted magnetic beam into the screw, which is allow us to measure the implant stability quotient.

Table 2 The implant modelling screw's geometrical parameters

\begin{tabular}{lc}
\hline Type of screw & Tapping \\
\hline Head type & Hexagonal \\
Length $(\mathrm{mm})$ & 13 \\
Diameter $(\mathrm{mm})$ & 3.9 \\
Core diameter $(\mathrm{mm})$ & 2.8 \\
Pitch $(\mathrm{mm})$ & 1.35 \\
Revolution & 8 \\
Thread profile & symmetric \\
Tapped hole type & M2 \\
\hline
\end{tabular}

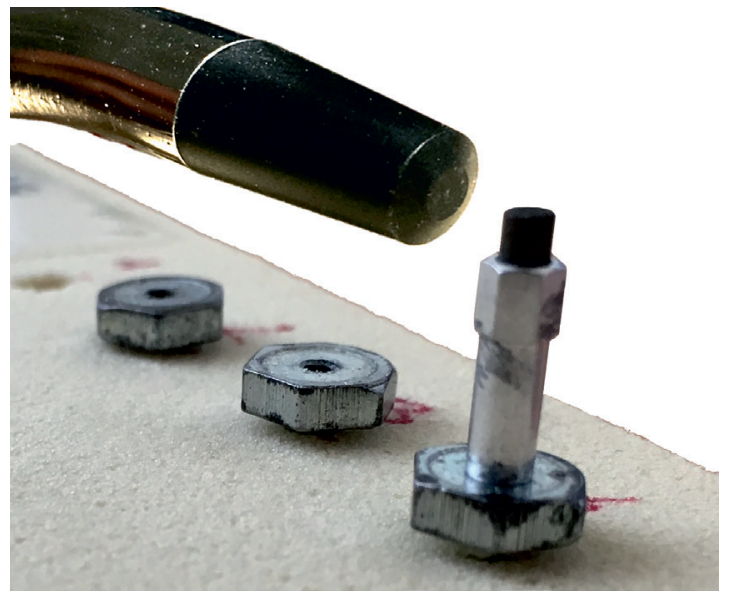

Fig. 3 ISQ measurement of the screws in bone modelling PUR solid foam. The measurement was made in four perpendicular direction. 
The simulation type was static stress analysis with linear elastic material models to simulate the displacements (micromotion) in standard loading cases. The reason why elastic material model was used is the fact, that after plastic deformation of the bone (in our case the PUR solid foam) the primary stability cannot be further interpreted. The simulation set up was similar with the measurements set up. The screw digital model was made with reverse engineering. The CAD screw 3D model was embedded in a cube $(15 \times 15 \times 15 \mathrm{~mm})$, which contained the negative form of the screw. For the screw-PUR block contact type was bonded used, to simulate the highest primary stability and in later stage the highest osseointegration (secondary stability) level. For the block outer surfaces constrain fixed was used, except the bone level surface.

\section{Results}

\subsection{Cross section analysis}

Three cross section analysis was made to see the compressed PUR solid foam material structure around the screws. From the lowest, medium and highest density of PUR solid foam were taken samples and grinded. The microscopy analysis of the grinded surfaces (Fig. 4) shows the solid foam cells deformation, the compressed area and the material continuity around the dental implant depending of the foam densities.

\subsection{Insertion Torque}

During the insertion of the screws, the monitoring of the insertion curve is a first stage of the analysis of the primary stability. If the graph does not show high drops, and continuously increases to the limit torque, then the implant stability will reach the expected primary stability value. The Fig. 5 shows the average insertion curves of the screws in different PUR solid foam block densities, with the SD range.
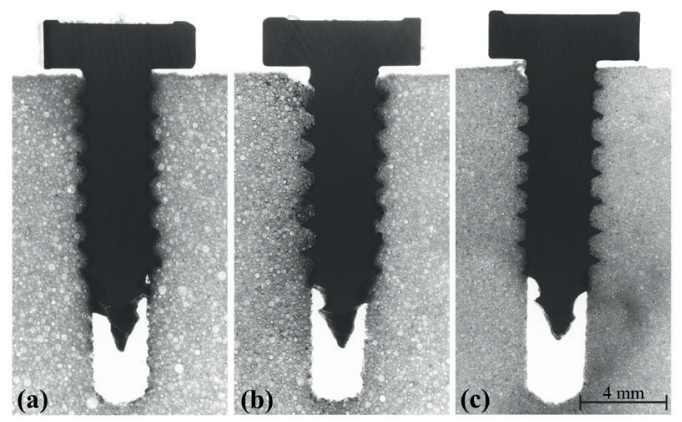

Fig. 4 Cross sections of inserted screws in different PUR solid foam densities.

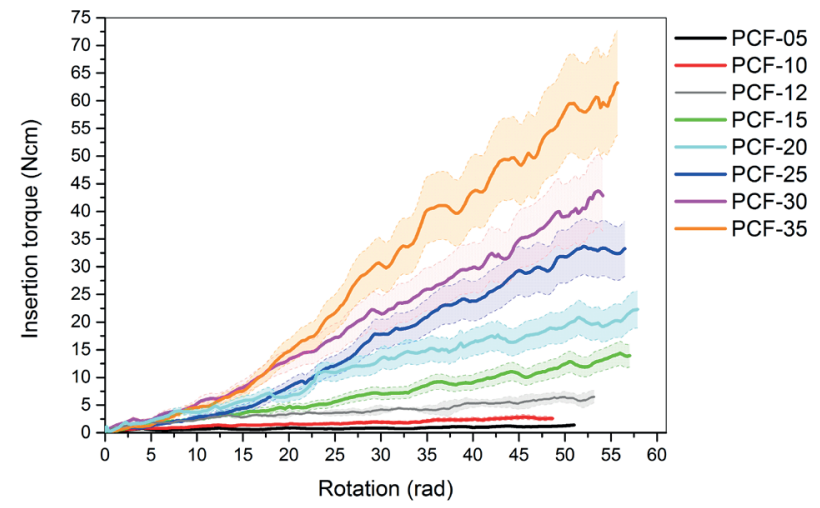

Fig. 5 The insertion torque curves of a screw in different PUR solid foam blocks, with SD.

\subsection{Calibration curve}

The calibration curve was determined from the measured primary stability ISQ values and micro mobility values (Table 3). On the basis of the measured point, a curve was fitted and the characteristic equation was determined. The ISQ as a function of the micro mobility shows how the screw's surrounding material properties influence the primary stability (Fig. 6).

Table 3 The measured values of ISQ and micro mobility.

\begin{tabular}{lcc}
\hline Type of solid foam & Micro mobility $(\mu \mathrm{m} / \mathrm{N})$ & ISQ $(-)$ \\
\hline PCF05 & 82.67 & 22.75 \\
PCF10 & 53.02 & 23.5 \\
PCF12 & 30.99 & 32.58 \\
PCF15 & 7.15 & 49.16 \\
PCF20 & 1.85 & 56.95 \\
PCF25 & 1.68 & 63.67 \\
PCF30 & 1.75 & 66.17 \\
PCF35 & 1.68 & 66.75 \\
\hline
\end{tabular}

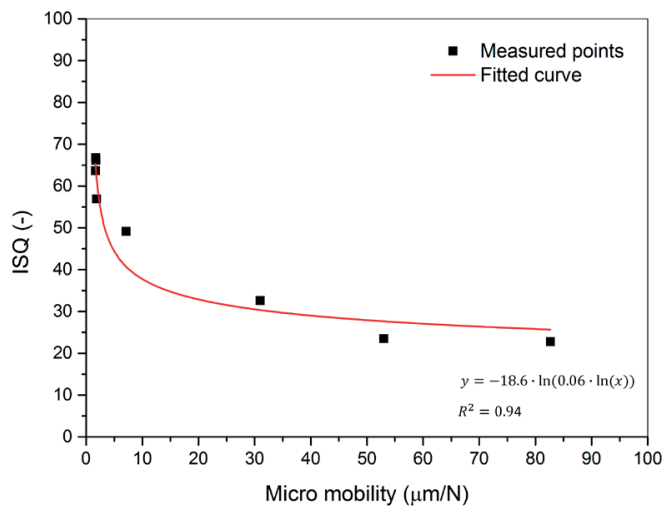

Fig. 6 The fitted curve and the characteristic equation, which shows how change the primary stability of the tapered screw in different type of solid foams. 


\subsection{Comparison of measured and simulated results}

To the calculation of the ISQ values the characteristic equation was used, which helps to convert the FEA simulated micro mobility values to ISQ (Table 4), which is used in the clinical life, and easier to evaluate as a primary stability indicator.

\section{Discussion}

The research shows a method how to determine in vitro a dental implant or any kind of screw geometry calibration curve and characteristic equation, which are the base correlation of a virtual ISQ stability analysis. The novelty of this study is the direct calculation of the ISQ stability values from the FEA simulated micro mobility result. Scientific studies analyses numerical methods to simulate the stress distribution around dental implants [34-41] but these stress results do not give any comparable information about the actual stability of the implant. It is not possible to determine direct form the simulated stress distribution the clinically used ISQ values.

To the calculation of the ISQ stability from FEA simulated micro mobility, three main steps needed during the in vitro measurement to insure, that the correlation between micro mobility and ISQ is correct.

1. During the in vitro measurements the insertion torque must be monitored and analyzed. If the torque graph does not show high drops, and continuously increases to the limit torque, then the implant sits well in the position, and the stability will reach the expected primary stability value. The general point in clinical use of dental implants is (according the insertion protocol of the implant manufacturer) to reach a maximum (peak) insertion torque value [42-45]. This one number does not contain the whole insertion procedure, and cannot warn

Table 4 The summary table of the measured and calculated ISQ values.

\begin{tabular}{|c|c|c|c|c|}
\hline \multirow{2}{*}{$\begin{array}{l}\text { Type of bone } \\
\text { modelling } \\
\text { PUR solid } \\
\text { foam block }\end{array}$} & \multicolumn{2}{|c|}{ Measured } & \multicolumn{2}{|c|}{ Calculated } \\
\hline & $\begin{array}{l}\text { Micro mobility } \\
\qquad(\mu \mathrm{m} / \mathrm{N})\end{array}$ & $\begin{array}{c}\text { ISQ } \\
(-)\end{array}$ & $\begin{array}{l}\text { Micro mobility } \\
\qquad(\mu \mathrm{m} / \mathrm{N})\end{array}$ & $\begin{array}{c}\text { ISQ } \\
(-)\end{array}$ \\
\hline PCF05 & 82.67 & 22.75 & 76.45 & 25.04 \\
\hline PCF10 & 53.02 & 23.5 & 56.37 & 26.39 \\
\hline PCF12 & 30.99 & 32.58 & 35.03 & 28.73 \\
\hline PCF15 & 7.15 & 49.16 & 10.12 & 36.72 \\
\hline PCF20 & 1.85 & 56.95 & 2.06 & 58.36 \\
\hline PCF25 & 1.68 & 63.67 & 1.84 & 61.53 \\
\hline PCF30 & 1.75 & 66.17 & 1.80 & 62.21 \\
\hline PCF35 & 1.68 & 66.75 & 1.74 & 63.31 \\
\hline
\end{tabular}

about high drops or growth area. This one number is not enough to give information about the insertion and primary stability of an implant. That is the reason why insertion torque curve need to be monitored and analyzed in vitro and in vivo as well [46-49].

2. The inserted implants have the same geometry, which geometries deform in different ways the surrounding material during in vitro examination (bone modelling standard PUR solid foam). The 2D microscopy analysis of the bone implant contact (BIC), where the solid foam cells deformation, the compressed area and the material continuity around the dental implant correlated to the implant stability. Studies where in vivo examination were done, 2D histology and histomorphometry analysis and 3D microCT were used to determine the correlation between BIC and implant stability depending bone densities, and healing stage [50-54]. These methods can be used just preclinically, and they are not suitable for monitoring during the healing period the change of the stability.

3. Clinically used direct dental implant stability measurement systems must be used, to check the implant primary stability. After the insertion of a dental implant there are not too many options to check or monitor in clinical life the stability. The most common used method is the imaging technology, specially the cone beam computer tomography (CBCT). The CBCT images give information about the bone stage around the dental implant, and approximately it is the possibility to determine the bone implant contact (BIC), but there is no option to determine psychically the implant stability [55-59]. Therefore is necessary to apply such a measuring method (Fig. 1, e.g. RFA), which gives information about direct implant stability and has physical content.

\section{Conclusion}

The possibility to determine in vitro the calibration curve in case of each kind of implant geometry opens the door to analyze during the lifetime the actual status (health and stability) of a dental implant. Thanks to the numerical simulation (FEA) further analysis are possible to predict the critical and the risk cases, when the implant will be endangered and influence the implant stability. During the simulation the bone structure and mechanical properties can be easily modifiable, and many simulation cases can be done in short time. Thanks to the calibration curve from the simulated micro mobility it is easy to calculate the clinical used ISQ values. 
A correlation and values, which represent the implant stability in three different ways, must be proved. These methods should be the following: biomechanical (e.g. insertion torque, micro mobility), histomorphometry (e.g. microscopy), clinical used direct stability method (e.g. RFA-ISQ).

The importance of the monitoring (clinically and simulated as well) of the implant stability during their lifetime

\section{References}

[1] Hosein, Y. K., Dixon, S. J., Rizkalla, A. S., Tassi A. "A novel technique for measurement of orthodontic mini-implant stability using the Osstell ISQ device", The Angle Orthodontist, 89(2), pp. 284-291, 2019. https://doi.org/10.2319/011518-46.1

[2] Zanetti, E. M., Pascoletti, G., Calì, M., Bignardi, C., Franceschini, G. "Clinical Assessment of Dental Implant Stability During Follow-Up: What Is Actually Measured, and Perspectives", Biosensors, 8(3), Article ID: 68, 2018.

https://doi.org/10.3390/bios8030068

[3] Abdulgani, A., Muhamad, A. H., Chlorokostas, G., Abdulgani, M. "Implant Stability: Methods and Recent Advances", IOSR Journal of Dental and Medical Sciences, 16(8), pp. 13-23, 2017. https://doi.org/10.9790/0853-1608021323

[4] Swami, V., Vijayaraghavan, V., Swami, V. "Current trends to measure implant stability", The Journal of Indian Prosthodontic Society, 16(2), pp. 124-130, 2016. https://doi.org/10.4103/0972-4052.176539

[5] Sachdeva, A., Dhawan, P., Sindwani, S. "Assessment of Implant Stability: Methods and Recent Advances", British Journal of Medicine and Medical Research, 12(3), pp. 1-10, 2016. https://doi.org/10.9734/BJMMR/2016/21877

[6] Mistry, G., Shetty, O., Shetty, S., Singh, R. D. "Measuring implant stability: A review of different methods", Journal of Dental Implants, 4(2), pp. 165-169, 2014. https://doi.org/10.4103/0974-6781.140891

[7] Atsumi, M., Park, S. H., Wang, H. L. "Methods used to assess im-plant stability: Current status", The International Journal of Oral \& Maxillofac Implants, 22(5), pp. 743-754, 2007.

[8] American Society for Testing and Materials "ASTM F543-17, Standard Specification and Test Methods for Metallic Medical Bone Screws", ASTM International, West Conshohocken, PA, USA, 2017. https://doi.org/10.1520/F0543-17

[9] International Organization for Standardization "ISO/TS 22911:2016 Dentistry - Preclinical evaluation of dental implant systems - Animal test methods", ISO, Geneva, Switzerland, 2016. [online] Available at: https://www.iso.org/obp/ui/\#iso:std:iso:ts:22911:ed-2:v1:en [Accessed: 18 February 2019]

[10] Chang, Y., Tambe, A. A., Maeda, Y., Wada, M., Gonda, T. "Finite element analysis of dental implants with validation: to what extent can we expect the model to predict biological phenomena? A literature review and proposal for classification of a validation process", International Journal of Implant Dentistry, 4(1), Article ID: 7, 2018.

https://doi.org/10.1186/s40729-018-0119-5 increases because the early detection of the stability change could save the implant osseointegration.

\section{Acknowledgement}

Special thanks to the Semmelweis University, Department of Oral Biology for the possibility the access to the Osstell machine, and to the department research fellows for their professional knowledge in the topic.

[11] Bicudo, P., Reis, J., Deus, A. M., Reis, L., Vaz, M. F. "Mechanical behaviour of dental implants", Procedia Structural Integrity, 1, pp. 26-33, 2016.

https://doi.org/10.1016/j.prostr.2016.02.005

[12] Chen, L., He, H., Li, Y., Li, T., Guo, X., Wang, R. "Finite element analysis of stress at implant-bone interface of dental implants with different structures", Transactions of Nonferrous Metals Society of China, 21(7), pp. 1602-1610, 2011. https://doi.org/10.1016/s1003-6326(11)60903-5

[13] Premnath, K., Sridevi, J., Kalavathy, N., Nagaranjani, P., Sharmila, M. R. "Evaluation of Stress Distribution in Bone of Different Densities Using Different Implant Designs: A ThreeDimensional Finite Element Analysis", The Journal of Indian Prosthodontic Society, 13(4), pp. 555-559, 2013. https://doi.org/10.1007/s13191-012-0189-7

[14] Chang, S. H., Lin, C. L., Hsue, S. S., Lin, Y. S., Huang, S. R. "Biomechanical analysis of the effects of implant diameter and bone quality in short implants placed in the atrophic posterior maxilla", Medical Engineering \& Physics, 34(2), pp. 153-160, 2012. https://doi.org/10.1016/j.medengphy.2011.07.005

[15] Rittel, D., Dorogoy, A., Haïat, G., Shemtov-Yona, K. "Resonant frequency analysis of dental implants", Medical Engineering \& Physics, 66, pp. 65-74, 2019. https://doi.org/10.1016/j.medengphy.2019.02.008

[16] Zanetti, E. M., Ciaramella, S., Calì, M., Pascoletti, G., Martorelli, M., Asero, R., Watts, D. C. "Modal analysis for implant stability assessment: Sensitivity of this methodology for different implant designs", Dental Materials, 34(8), pp. 12351245, 2018.

https://doi.org/10.1016/j.dental.2018.05.016

[17] Li, W., Lin, D., Rungsiyakull, C., Zhou, S., Swain, M., Li, Q. "Finite element based bone remodeling and resonance frequency analysis for osseointegration assessment of dental implants", Finite Elements in Analysis and Design, 47(8), pp. 898-905, 2011. https://doi.org/10.1016/j.finel.2011.03.009

[18] Sennerby, L. "20 years of experience with resonance frequency analysis", Implantologie, 21(1), pp. 21-33, 2013.

[19] Herrero-Climent, M., Santos-García, R., Jaramillo-Santos, R., Romero-Ruiz, M. M., Fernández-Palacin, A., Lázaro-Calvo, P., Bullón, P., Ríos-Santos, J. V. "Assessment of Osstell ISQ's reliability for implant stability measurement: A cross-sectional clinical study", Medicina Oral Patología Oral y Cirugia Bucal, 18(6), pp. e877-e882, 2013.

https://doi.org/10.4317/medoral.19120 
[20] Baftijari, D., Benedetti, A., Kirkov, A., Iliev, A., Stamatoski, A., Baftijari, F., Deliverska, E. G., Gjorgievska, E. "Assessment of Primary and Secondary Implant Stability by Resonance Frequency Analysis in Anterior and Posterior Segments of Maxillary Edentulous Ridges", Journal of IMAB, 24(2), pp. 2058-2064, 2018. https://doi.org/10.5272/jimab.2018242.2058

[21] Levin, B. P. "The Correlation Between Immediate Implant Insertion Torque and Implant Stability Quotient", The International Journal of Periodontics \& Restorative Dentistry, 36(6), pp. 833-840, 2016. https://doi.org/10.11607/prd.2865

[22] Shokri, M., Daraeighadikolaei, A. "Measurement of Primary and Secondary Stability of Dental Implants by Resonance Frequency Analysis Method in Mandible", International Journal of Dentistry, 2013, Article ID: 506968, 2013.

https://doi.org/10.1155/2013/506968

[23] Sugiura, T., Yamamoto, K., Horita, S., Murakami, K., Kirita, T. "Micromotion analysis of different implant configuration, bone density, and crestal cortical bone thickness in immediately loaded mandibular full-arch implant restorations: A nonlinear finite element study", Clinical Implant Dentistry and Related Research, 20(1), pp. 43-49, 2018.

https://doi.org/10.1111/cid.12573

[24] Kawahara, H., Kawahara, D., Hayakawa, M., Tamai, Y., Kuremoto, T., Matsuda, S. "Osseointegration under immediate loading: biomechanical stress-strain and bone formation resorption", Implant Dentistry, 12(1), pp. 61-68, 2003.

[25] Brunski, J. B. "In Vivo Bone Response to Biomechanical Loading at the Bone/Dental-Implant Interface", Advances in Dental Research, 13(1), pp. 99-119, 1999.

https://doi.org/10.1177/08959374990130012301

[26] Szmukler-Moncler, S., Salama, H., Reingewirtz, Y., Dubruille, J. H. "Timing of loading and effect of micromotion on bone-dental implant interface: review of experimental literature", Journal of Biomedical Materials Research, 43(2), pp. 192-203, 1998.

https://doi.org/10.1002/(SICI)1097-4636(199822)43:2<192::AIDJBM14>3.0.CO;2-K

[27] Pagliani, L., Sennerby, L., Petersson, A., Verrocchi, D., Volpe, S., Andersson, P. "The relationship between resonance frequency analysis (RFA) and lateral displacement of dental implants: an in vitro study", Journal of Oral Rehabilitation, 40(3), pp. 221-227, 2013. https://doi.org/10.1111/joor.12024

[28] Trisi, P., Berardini, M., Falco, A., Podaliri Vulpiani, M. "Validation of value of actual micromotion as a direct measure of implant micromobility after healing (secondary implant stability). An in vivo histologic and biomechanical study", Clinical Oral Implants Research, 27(11), pp. 1423-1430, 2016.

https://doi.org/10.1111/clr.12756

[29] Trisi, P., Carlesi, T., Colagiovanni, M., Perfetti, G. "Implant Stability Quotient (ISQ) vs Direct in Vitro Measurement of Primary Stability (Micromotion): Effect of Bone Density and Insertion Torque", Journal of Osteology and Biomaterials, 1(3), pp. 141-151. 2010.

[30] Brizuela-Velasco, A., Álvarez-Arenal, Á., Gil-Mur, F., HerreroCliment, M., Chávarri-Prado, D., Chento-Valiente, Y., DieguezPereira, M. "Relationship Between Insertion Torque and Resonance Frequency Measurements, Performed by Resonance Frequency Analysis, in Micromobility of Dental Implants: An In Vitro Study", Implant Dentistry, 24(5), pp. 607-611, 2015.

https://doi.org/10.1097/id.0000000000000318
[31] American Society for Testing and Materials "ASTM F183908(2016) Standard Specification for Rigid Polyurethane Foam for Use as a Standard Material for Testing Orthopaedic Devices and Instruments", ASTM International, West Conshohocken, PA, 2016.

https://doi.org/10.1520/F1839-08R16

[32] Sawbones Biomechanical Catalog, [online] Available at: www. sawbones.com/wp/wp-content/uploads/2017/04/FINAL_ Biomechanical_Catalog.pdf [Accessed: 04 March 2019]

[33] Osstell AB "Clinical guidelines", [online] Available at: https:/goo. gl/f9au6s [Accessed: 06 February 2019]

[34] Kumar, G. A., Kovoor, L. C., Oomen, V. M. "Three-dimensional finite element analysis of the stress distribution around the implant and tooth in tooth implant-supported fixed prosthesis designs", Journal of Dental Implants, 1(2), pp. 75-79, 2011.

https://doi.org/10.4103/0974-6781.91283

[35] Chou, H. Y., Müftü, S. "Simulation of peri-implant bone healing due to immediate loading in dental implant treatments", Journal of Biomechanics, 46(5), pp. 871-878, 2013. https://doi.org/10.1016/j.jbiomech.2012.12.023

[36] Dhatrak, P., Shirsat, U., Sumanth, S., Deshmukh, V. "Finite Element Analysis and Experimental Investigations on Stress Distribution of Dental Implants around Implant-Bone Interface", Materials Today: Proceedings, 5(2), pp. 5641-5648, 2018. https://doi.org/10.1016/j.matpr.2017.12.157

[37] da Costa Valente, M. L., de Castro, D. T., Macedo, A. P., Shimano, A. C., dos Reis, A. C. "Comparative analysis of stress in a new proposal of dental implants", Materials Science and Engineering: C, 77, pp. 360-365, 2017. https://doi.org/10.1016/j.msec.2017.03.268

[38] Lee, H., Park, S., Noh, G. "Biomechanical analysis of 4 types of short dental implants in a resorbed mandible", The Journal of Prosthetic Dentistry, 121(4), pp. 659-670, 2019. https://doi.org/10.1016/j.prosdent.2018.07.013

[39] Papavasiliou, G., Kamposiora, P., Bayne, S. C., Felton, D. A. "3D-FEA of osseointegration percentages and patterns on implant-bone interfacial stresses", Journal of Dentistry, 25(6), pp. 485-491, 1997. https://doi.org/10.1016/s0300-5712(96)00061-9

[40] Chang, H. S., Chen, Y. C., Hsieh, Y. D., Hsu, M. L. "Stress distribution of two commercial dental implant systems: A three-dimensional finite element analysis", Journal of Dental Sciences, 8(3), pp. 261-271, 2013. https://doi.org/10.1016/j.jds.2012.04.006

[41] Kurniawan, D., Nor, F. M., Lee, H. Y., Lim, J. Y. "Finite element analysis of bone-implant biomechanics: refinement through featuring various osseointegration conditions", International Journal of Oral and Maxillofacial Surgery, 41(9), pp. 1090-1096, 2012. https://doi.org/10.1016/j.ijom.2011.12.026

[42] Goswami, M. M., Kumar, M., Vats, A., Bansal, B. A. S. "Evaluation of dental implant insertion torque using a manual ratchet", Medical Journal Armed Forces India, 71(Supplement 2), pp. S327-S332, 2015. https://doi.org/10.1016/j.mjafi.2013.07.010

[43] Makary, C., Rebaudi, A., Mokbel, N., Naaman, N. "Peak Insertion Torque Correlated to Histologically and Clinically Evaluated Bone Density", Implant Dentistry, 20(3), pp. 182-191, 2011. https://doi.org/10.1097/id.0b013e31821662b9 
[44] Hakim, S. G., Glanz, J., Ofer, M., Steller, D., Sieg, P. "Correlation of cone beam CT-derived bone density parameters with primary implant stability assessed by peak insertion torque and periotest in the maxilla", Journal of Cranio-Maxillofacial Surgery, 47(3), pp. 461-467, 2019.

https://doi.org/10.1016/j.jcms.2019.01.002

[45] Burdette Dental Lab "Implant Torque Specification Guide", [pdf] Available at: www.burdettedental.com/wp-content/ uploads/2016/11/7204-Torque-Spec-Sheet.V5.web_.pdf [Accessed: 04 January 2019]

[46] Pammer, D., Bognár, E. "Insertion Torque Function Analysis of Novel Dental Implant Geometry", In: Jobbágy, Á. (ed.) First European Biomedical Engineering Conference for Young Investigators, IFMBE Proceedings, Springer, Singapore, Singapore, 50, pp. 83-86, 2015.

https://doi.org/10.1007/978-981-287-573-0_21

[47] Baldi, D., Lombardi, T., Colombo, J., Cervino, G., Perinetti, G., Di Lenarda, R., Stacchi, C. "Correlation between Insertion Torque and Implant Stability Quotient in Tapered Implants with KnifeEdge Thread Design", BioMed Research International, 2018, Article ID: 7201093, 2018. https://doi.org/10.1155/2018/7201093

[48] Dorogoy, A., Rittel, D., Shemtov-Yona, K., Korabi, R. "Modeling dental implant insertion", Journal of the Mechanical Behavior of Biomedical Materials, 68, pp. 42-50, 2017. https://doi.org/10.1016/j.jmbbm.2017.01.021

[49] Di Stefano, D. A., Arosio, P., Gastaldi, G., Gherlone, E. "The insertion torque-depth curve integral as a measure of implant primary stability: An in vitro study on polyurethane foam blocks", The Journal of Prosthetic Dentistry, 120(5), pp. 706-714, 2018. https://doi.org/10.1016/j.prosdent.2017.04.012

[50] Farkasdi, S., Pammer, D., Rácz, R., Hriczó-Koperdák, G., Szabó, B. T., Dobó-Nagy, Cs., Kerémi, B., Blazsek, J., Cuisinier, F., Wu, G., Varga, G. "Development of a quantitative preclinical screening model for implant osseointegration in rat tail vertebra", Clinical Oral Investigations, 23(7), pp. 2959-2973, 2019. https://doi.org/10.1007/s00784-018-2661-1

[51] Wu, X., Deng, F., Wang, Z., Zhao, Z., Wang, J. "Biomechanical and histomorphometric analyses of the osseointegration of microscrews with different surgical techniques in beagle dogs", Oral Surgery, Oral Medicine, Oral Pathology, Oral Radiology, and Endodontology, 106(5), pp. 644-650, 2008. https://doi.org/10.1016/j.tripleo.2008.05.031
[52] Gehrke, S. A., Maté Sánchez de Val, J. E., Fernández Domínguez, M., de Aza Moya, P. N., Gómez Moreno, G., Calvo Guirado, J. L. "Effects on the osseointegration of titanium implants incor-porating calcium-magnesium: a resonance frequency and histo-morphometric analysis in rabbit tibia", Clinical Oral Implants Research, 29(7), pp. 785-791, 2018. https://doi.org/10.1111/clr.12909

[53] Dhaliwal, J. S., Albuquerque, R. F., Murshed, M., Feine, J. S. "Osseointegration of standard and mini dental implants: a histomorphometric comparison", International Journal of Implant Dentistry, 3(1), Article ID: 15, 2017. https://doi.org/10.1186/s40729-017-0079-1

[54] Choi, J. Y., Park, J. I., Chae, J. S., Yeo, I. S. L. "Comparison of micro-computed tomography and histomorphometry in the measurement of bone-implant contact ratios", Oral Surgery, Oral Medicine, Oral Pathology and Oral Radiology, 128(1), pp. 87-95, 2019. https://doi.org/10.1016/j.oooo.2018.12.023

[55] Hsu, J. T., Wu, A. Y. J., Fuh, L. J., Huang, H. L. "Effects of implant length and 3D bone-to-implant contact on initial stabilities of dental implant: a microcomputed tomography study", BMC Oral Health, 17(1), Article ID: 132, 2017. https://doi.org/10.1186/s12903-017-0422-1

[56] Mangano, C., Luongo, F., Migliario, M., Mortellaro, C., Mangano, F. G. "Combining Intraoral Scans, Cone Beam Computed Tomography and Face Scans: The Virtual Patient", Journal of Craniofacial Surgery, 29(8), pp. 2241-2246, 2018. https://doi.org/10.1097/SCS.0000000000004485

[57] Figliuzzi, M., Giudice, A., Mangano, F. G., Fortunato, L. "A Direct Metal Laser Sintering (DMLS) Root Analogue Implant Placed in the Anterior Maxilla: Case Report", Periodontics and Prosthodontics, 2(1), Article ID: 6, 2016. https://doi.org/10.21767/2471-3082.100011

[58] Mangano, F., Chambrone, L., van Noort, R., Miller, C., Hatton, P., Mangano, C. "Direct Metal Laser Sintering Titanium Dental Implants: A Review of the Current Literature", International Journal of Biomaterials, 2014, Article ID: 461534, 2014. https://doi.org/10.1155/2014/461534

[59] Sumer, A. P., Caliskan, A., Uzun, C., Karoz, T. B., Sumer, M., Cankaya, S. "The evaluation of palatal bone thickness for implant insertion with cone beam computed tomography", International Journal of Oral and Maxillofacial Surgery, 45(2), pp. 216-220, 2016. https://doi.org/10.1016/j.ijom.2015.09.012 